\section{SOME CASES OF VERNAL CATARRH.}

\section{BY T. HARRISON BUTLER, M.D. OXON.,}

HONORARY OPHTHALMIC SURGEON TO THE COVENTRY AND WARWICKHIRE HOSPITAI; IATE ASSISTANT SUHGEON TO THE BRITISH OPHTHALMIC HOSPITAL, JEHUSALEM.

Spring catarrh is not uncommon in Palestine and Syria if care be taken to differentiate it from those types of trachoma which simulate it. In some cases, especially if the disease be confined to the lids, the differential diagnosis may present some difficulty. The enormously hypertrophied papillæ seen in some severe cases of untreated and neglected trachoma may by mutual pressure show the same polyhedral basalt. jike appearance which is so characteristic of vernal catarrh. The trachomatous lid is, however, more congested and the swollen papillæa are red and bleed easily. In vernal catarrh the granular elevations are pink rather than red and they are very hard. The pannus which is so constantly associated with these severe cases of trachoma is entirely unlike the corneal lesions of spring catarrh. In many cases the two diseases coexist and so increase the difficulties of diagnosis.

I have selected the following four cases from those which came under my care at the British Ophthalmic Hospital as topical of the disease in Syria and the Exst.

CASE 1-The patient, an Arab, aged 16 zears, a native of Beyrût, came under my care in June. 1906, suffering from spring catarrh in a very severe form. His history, which was attested by letters from the medical men who had attended him, was as follows. The disease commenced eight years ago as "trachoma" with " pannus" and "keratitis." It had steadily increased in severity. The condition was worse in summer than in winter. No relatives were similarly affected. The boy had been treated internally with cod-liver oil, iron, and arsenic. The lids had been painted with silver nitrate, with solutions of sublimate of mercury, and with

Fig. 1.

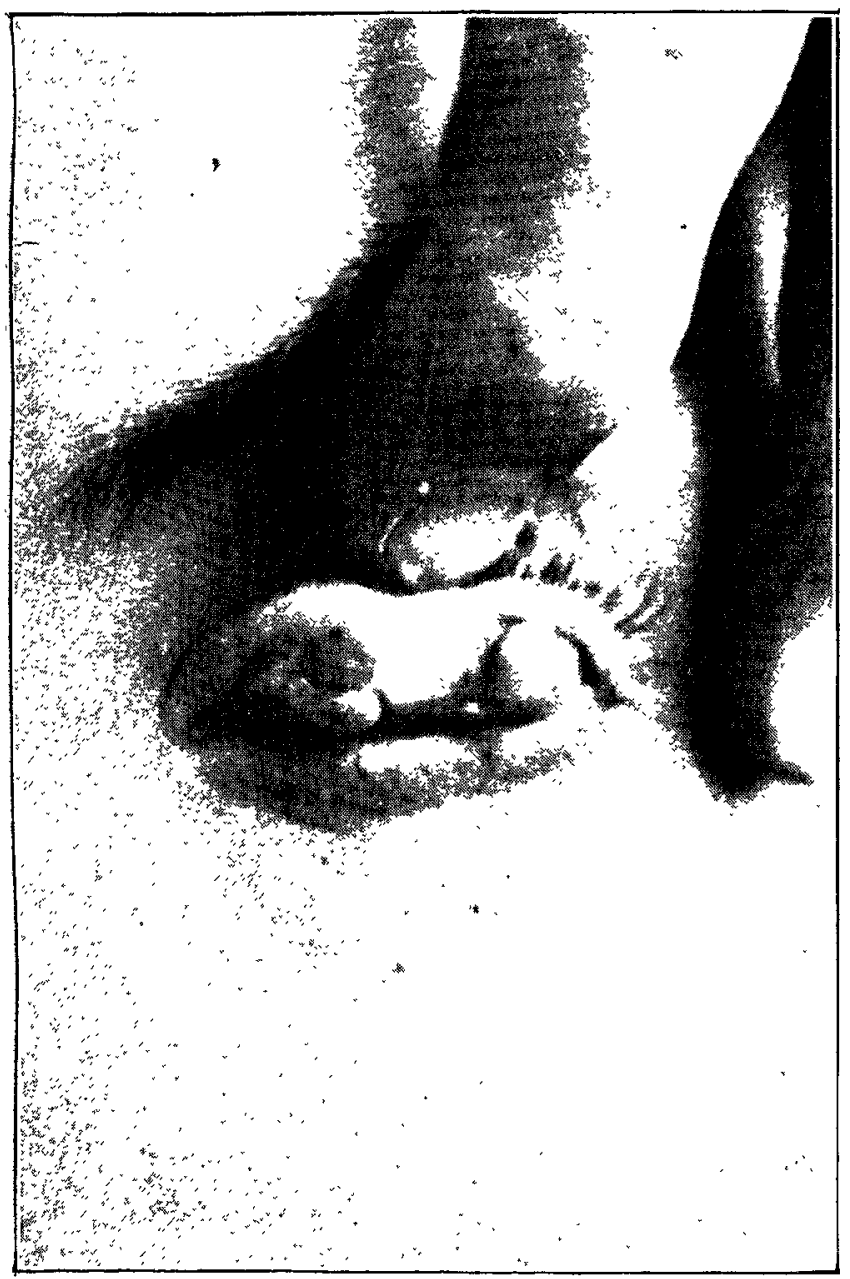

Showing growths on inner sid, of upper eyelid.

"free iodine." They had been rubbed with solid copper sulphate. The patient had used ointments containing ichihyol, yellow oxide of mercury, dionine, and cocaine. He had been treated with adrenalin in a strength of 1 in 1000 . "The lids had been exposed to the "vapour of calomel," they had undergone "brossage," and had been cauterised with the actual cautery. The redundint growths had been removed with scissors and peritomy had been performed. In short, duing a period of eight years the patient bad undergone every known form of treatment, and, far from improving, had steadily got worse.

The patient's condition on admission was as follows. He was an unhealthy looking boy of a decidedly lymphatic type. He had well-marked bilateral ptosis. Both upper lids were covered by large pedunculated flat growths, which are shown in the photograph of the everted lid here reproduced. (Fig. 1.) Between these large masses the lids showed the tessellated granulations typical of the disease. The upper lids were much thickened and the conjunctiva felt hard and gritty. The peripheral part of each cornea was covered by a mass of jelly-like tissue which formed a ring round the cornea. At the corneal margin it was raised some two millimetres from the general corneal level and it shelved down towards the central portion of the cornea and centrifugally into the ocular conjunctiva, which was thickened and opaque looking. (Fig. 2.) The c sutral part

Fig. 2.

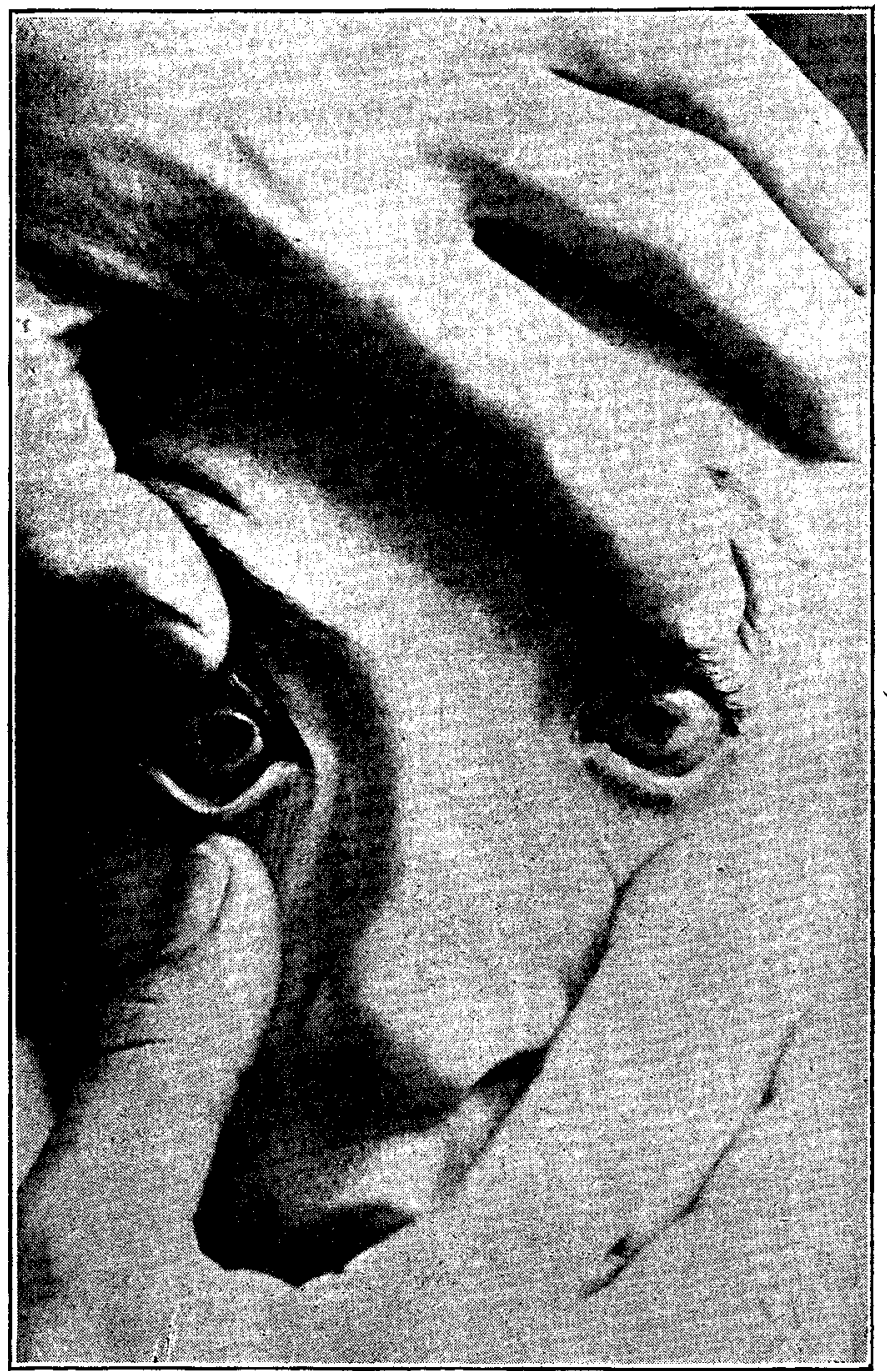

Showfng swelling of conjunctiva.

of the cornea was faintly nebulous. The corneal growth was a pinky-white colour. There were very little conjunctival injection and no circumcorneal injection. There were at times some lacrymation and photophobia. V.R. $=\frac{{ }^{6}}{30} ;$ not improved. V.L. $={ }^{6} \sigma$; not improved. The patient was armitted to the British Ophthalmic Hospital and anæsthetised with ether. The large growths were exci-ed with scissors and the lids were well scraped with a Volkmann's spoon. The granulations were hard and grated like fibro. rartilage. On the next day there was no reaction and be complained of no pain.

The patient remained in hospital for 14 days. Every day an ointment was massaged into the lids morning and evening having the following composition: Hydrargyri oxidi flavi, 0.05 gramme ; atropine sulphate, 005 gramme; and yellow vaseline, 5 grammes. On leaving the hospital the patient's condition was very much improved. The pericorneal growth at first much elevated and pink had greatly subsided. It was 
no longer pink but whitish. It was not jelly-like and elevated but firm, cicatricial, and but slightly raised above the general corneal surface. There was less ptosis and he felt much more comfortable. The patient was kept under observation for some time and returned home much benefited. As an out-patient he used the following prescription with much advantage as an ointment: Hydrargyri oxidi Hlavi, 0.05 gramme; dionine, 0.05 gramme; and yellow vaseline, 5 grammes.

This case was a very severe one both as regards the lids and the cornea. It was probably too severe and too chronic for a cure to be expected. The condition of the lids and corneæ is well shown in the illustrations. When the redundant tissue had been reduced by operation, simple treatment with yellow oxide and atropine resulted in marked alleviation of the disease.

CAsE 2.-The patient, a male European, aged 14 years, first attended the hospital in October, 1905, and remained under observation for about nine months. The condition of the eyes had been first noticed some months before he attended. When first seen he presented the following condition. Each cornea was surrounded by a raised ring of pinkish-white tissue of a jelly-like consistency. Towards the centre of the cornea it was divided ap into ovoid discrete masses of translucent gelatinous material which coalesced centrifugally and merged into the ocular conjunctiva. This ring was about two millimetres wide at the widest part. The centre of the cornea was clear. The palpebral conjunctiva covering the lower lid was much

FiG. 3.

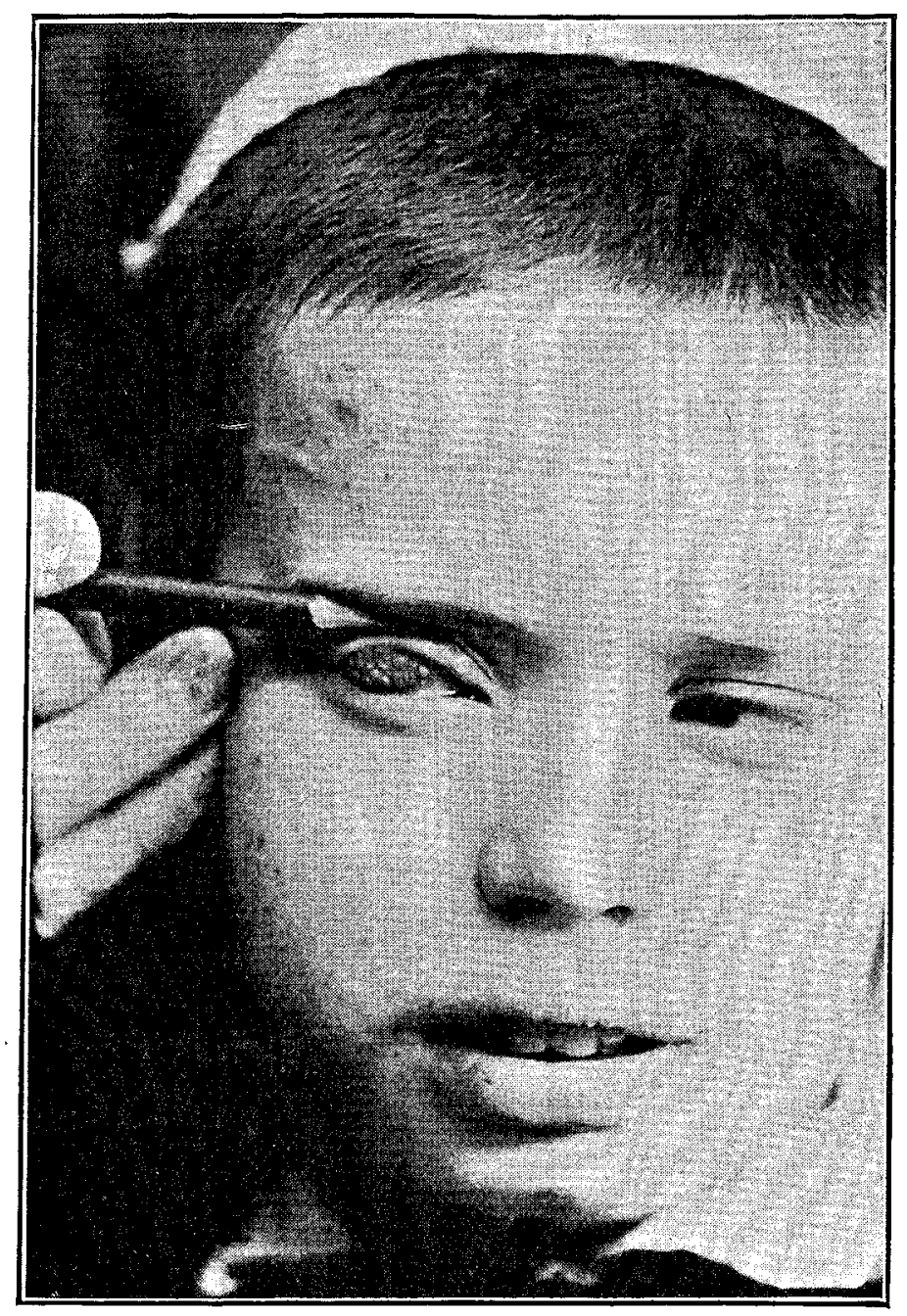

Showing flattened raspberry-like growth.

thickened and swollen. This thickening was continuous with a nodular thickened mass in the ocular conjunctiva and the lower cul-de-sac. This mass again merged into the pericorneal growth. The upper lids were thickened and the conjunctiva was congested and hard. It showed a fine tessellation but unless careful inspection was made this was not very obvious. There was on the right upper lid a flat sessile growth about three millimetres across. The patient complained of no subjective symptoms and the conjunctivæ were not injected. He was treated with 1 per cent. yellow oxide ointment well massaged in three times a day. After nine months of this treatment there was a very marked improvement. The pericorneal growth of the right eye had almost disappeared and the growth on the right lid could not be seen. A photograph taken at the end of nine months of treatment shows the pericorneal thickening and the nodular thickened condition of the conjunctiva. The localised thickening, now much less than formerly, can also be made out. In this case the stress of the disease fell upon the corneæ, the lids not being much affected.

CASE 3.-The patient, aged 11 years, was first seen in July, 1906. He was brought by his mother because his eyes were red. No history could be obtained of the condition being worse in summer nor did his mother know how long the disease had existed. Both upper lids were covered by large, hard granulations roughly hexagonal in shape. These are well-shown in the reproduced photograph of the everted lid. (Fig. 3.) Each cornea was surrounded by a very faint jelly-like ring of raised tissue, but it was so faint that were the lids not so typically affected it might easily be overlooked. The ocular conjunctivæ appeared to be normal. There was no injection of the conjunctivæ, but some lacrymation and photophobia were present. This case was treated for some time with the yellow oxide ointment combined with atropine. At the end of two months the condition was un. changed. The parents were averse to operative measures. In this patient the lids were severely affected, the cornea hardly at all.

- CASI 4.-The first three cases were all in young boys, but Case 4 was that of an adult Arab, aged 40 years, who came up for treatment in 1904. The left npper lid was covered with large cubical granulations arranged in short thick columns like a basaltic formation. Fach cube was about 1.5 millimetres square. The appearance of the lid was very similar to that of Case 3 , but the granulations were larger and deeper (more raised from the tarsus). The granulations were very hard and gritty to the touch. There was a large staphyloma involving nearly the whole of the cornea; the right cornea was nebulous. There was no typical affection of the cornea. The patient came to the hospital complaining more of the staphyloma than of the lid condition. The granulations were expressed with Knapp's roller forceps, but they were so hard and tough that great force was necessary to remove them. The lids were then treated with yellow oxide of mercury ointment. When last seen the lid was smooth and resembled a tiled pavement.

My experience has been that the treatment of spring catarrh is most unsatisfactory. I think that any pedunculated growth should be removed with scissors, large granulations with Knapp's roller forceps and Volkmann's spoon. Grady's forceps, excellent as the instrument is for expressing trachoma, will have little effect on the tough tissues in vernal catarrh. Such treatment, followed by the yellow oxide of mercury ointment well massaged in, has in my hands yielded the best results. I believe that copper sulphate does harm. At the present time I have a mild case under treatment with adrenalin which appears to me to have improved the condition.

\section{CLINICAL OBSERVATIONS ON THE ORIGIN OF FEVER.}

\section{BY ARNOLD LORAND, M.D. VIEN.}

From the moment of our birth we are constantly exposed to the incessant attacks of uncounted bacteria and to the effects of a large amount of poisonous material formed within our body or introduced from without, and if we survive this ceaseless battle it is due to the powerful weapon we possess in the internal secretion of the ductless glands, especially of the thyroid gland. That this gland possesses very energetic antitoxic properties can be shown by the fact that when it is extirpated animals or persons very readily acquire infectious diseases of all sorts. Thus, the late Professor Charrin (1) of Paris showed several years ago how readily dogs that have lost their thyroid succumb to all possible infections. Professor W. S. Greenfield (2) of Edinburgh has found that persons suffering from myxodema (athyroidia) very often die from tuberculosis, and Professor $\mathrm{Pel}(3)$ of Amsterdam found a great frequency of tuberculosis

I The parenthetical numbers throughout the article refer to the bibliography at the end. 